\title{
Comparison of the Efficacy of Prophylactic Intraligamentary Injection of Piroxicam Versus Mepivacaine for Management of Post-endodontic Pain in Posterior Teeth: (Double Blind Randomized Clinical Trial)
}

\section{Hend Hassan Swellam ${ }^{1 *}$, Hebatallah Mohamed Elfar ${ }^{2}$ and Sherif Adel El khodary ${ }^{3}$}

${ }^{1}$ Master of Endodontics, Faculty of Dentistry, Cairo University, Egypt

${ }^{2}$ Professor of Endodontics, Faculty of Dentistry, Cairo University, Egypt

${ }^{3}$ Associate Professor of Endodontics, Faculty of Dentistry, Cairo University, Egypt

*Corresponding Author: Hend Hassan Swellam, Master of Endodontics, Faculty of

Dentistry, Cairo University, Egypt.
Received: September 24, 2021

Published: November 10, 2021

(C) All rights are reserved by Hend Hassan

Swellam., et al.

\begin{abstract}
The aim of this research was to evaluate the effect of piroxicam (feldene) on reducing the pain after single visit endodontic treatment, a non-selective non-steroidal anti-inflammatory drug. Twenty-six patients, aged between 25 and 50 years with irreversible pulpitis and symptomatic apical periodontitis in mandibular molar teeth were randomly divided into two groups. The experimental group received intraligamentary injections totaling $0.4 \mathrm{~mL}$ of piroxicam, while the control group received the same amount of intraligamentary mepivacaine.

Single visit root canal treatment was performed by a single endodontist. Numeric Rating Scale was used to record pain before treatment and at 4, 8, 12, 24 and 48 h postoperatively. The decrease in the intensity of post-treatment pain between the two groups was statistically significant. Intraligamentary injection of piroxicam can be considered an effective method for decreasing post-endodontic pain.
\end{abstract}

Keywords: Post-endodontic Pain; Mepivacaine; Teeth

\section{Introduction}

Pain following endodontic treatment is one of the most common studied issues in endodontics. Post-endodontic pain results from instrumentation and/or obturation of the canal(s) [1]. Pain is commonly severe in the first $48 \mathrm{~h}$ and gradually decreases (if present) with time until usually disappearing after 7-10 days [2]. Although the pain may not suggest endodontic failure, management of this pain is usually more important to the patient than the success or the failure of the treatment [3]. Several studies agreed that symptomatic cases have higher incidence of post-operative pain. The incidence of post-operative pain associated with previ- ously symptomatic teeth was $15.9 \%$, compared with $7.1 \%$ for asymptomatic teeth [4].

Endodontic treatment is usually effective for reliving the pain, but not immediate especially after single visit endodontic treatment. Post-treatment analgesics are needed in many of endodontic cases [5]. Long-acting local anaesthetics prevent the dispersion of impulses along the peripheral nerves. Opioids prevent the central mechanisms of pain perception and hyperalgesia [6].

Non-steroidal anti-inflammatory drugs (NSAIDs) and glucocorticoids manage pain through preventing the inflammatory 
mediators [7]. The blocking of the inflammatory process is one of the most significant ways to decrease or prevent pain during and after treatment. NSAIDs have been the traditional treatment for mild and moderate pain. A study by Elzaki., et al. (2016) that evaluated the effect of paracetamol alone and in association with three different non-steroidal anti-inflammatory drugs for management of post-endodontic pain proved that combined use of ibuprofen/ paracetamol, taken instantly after initialism of endodontic therapy and root canal preparation in teeth with irreversible pulpitis decreased post-endodontic pain [8].

A systematic review and meta-analysis by Smith., et al. (2017) conducted on non-steroidal anti-inflammatory drugs (NSAIDs) which frequently used to control and manage endodontic postoperative pain showed that NSAIDS are effective in decreasing postoperative endodontic pain overall. Meta-analysis showed that the dose of ibuprofen $600 \mathrm{mg}$ is more successful than placebo at 6 hours postoperatively. It was proved that a combined use of ibuprofen $600 \mathrm{mg}$ and acetaminophen $1000 \mathrm{mg}$ had more significant effect than placebo [9].

Many double-blinded placebo-controlled clinical trials have showed that NSAIDs are very effective for management of pain resulting from surgical, periodontal and endodontic procedures. Double-blind clinical trials have shown that an NSAID, ketorolac tromethamin, when administrated intraorally or intramuscularly, generates effective analgesia in patients with severe pain before actual treatment. It is also proved that the intraligamental injection method provides the administration of anti-inflammatory drugs directly in the periapical intraosseous region $[10,11]$.

A study managed by Atbaei and Mortazavi (2012) concluded that piroxicam, which is non-selective NSAID with a half-life of 50 hours produced a significant decrease in postoperative endodontic pain when used through intraligamental injection way. The piroxicam group experienced less pain significantly after 48 hours than lidocaine group [12]. The aim of the current study was to see the successfulness of intraligamental injection of piroxicam in management of post-endodontic pain in comparison with mepivacaine after single visit root canal treatment.

\section{Materials and Methods}

Twenty -six Patients were signed up from the department of endodontics emergency clinic in the new building, Faculty of Dentistry, Cairo University. The study protocol and the informed consent sheets were accepted by the Research Ethics Committee (REC) regarding the scientific content and adherence with relevant research and human subject's rules. The treatment steps, purpose of the study and potential side effects were fully demonstrated for all the participants. Participants were requested to apply the general instructions and to sign an informed consent form that clarify the study aim.

Inclusion criteria for accepted participants were:

- $\quad$ Medically free patients.

- $\quad$ Both male and female.

- $\quad$ Age of patients from 25-50 years.

- Positive patient's acceptance for participation in the study

- Lower molar teeth with acute irreversible pulpitis and symptomatic apical periodontitis which is proved by clinical and radiographic examination.

- $\quad$ Patients who can follow the instructions of Numeric Rating Scale (NRS).

- $\quad$ Patients able to apply the informed consent signal.

Exclusion criteria

- $\quad$ Pregnant or lactating female patients.

- $\quad$ patients with compromised medical diseases.

- Patients with numerous teeth that need endodontic treatment to avoid the potential of referred pain.

- Psychological disturbance.

- $\quad$ Patient who has taken analgesic or anti-inflammatory drugs 12 hours before treatment

A randomized code indicated whether drug or placebo was aimed to be given to each patient and the code was not opened until the study is finished. The participant and the operator did not recognize whether placebo or drug was administrated. So, the design of the clinical trial was random and double blinded.

Patients were organized into two equal groups, group-A (experimental group) and group-B (control group). All treatment steps were done by one operator. Pain scale chart was given to each patient to rate his/her pain level before endodontic treatment as preoperative reading on a NRS scale (which was translated to Arabic). 
Patients will be anaesthetized with standard injections which is nerve block local anesthesia (using aspirating syringe with 27 -gauge, long needle) with $1.8 \mathrm{ml}$ of $2 \%$ mepivacaine containing 1:100,000 epinephrine. After obtaining profound anesthesia (lip numbness then tooth was examined with a cold sensitivity test, to confirm the anesthetic success).

Both groups received Intraligamentary injection after the nerve block anesthesia and before the root canal treatment.

The experimental group (group A) will receive intraligamentary injection of $0.4 \mathrm{ml}$ of $20 \mathrm{mg} / \mathrm{ml}$ piroxicam using specific intraligamentary dental syringe (Figure 1) and a short disposable needle with 27 gauge. The needle will be applied in the gingival sulcus at a 30 - degree angle to the long axis of the molar tooth then the operator will make more pressure apically until the needle forced into the periodontal ligament between the tooth and the alveolar crest of the bone $(0.2 \mathrm{ml}$ will be injected on each side of the tooth mesially and distally).

The control group (group B) will receive supplemental intraligamentary injection of $0.4 \mathrm{~mL}$ of $2 \%$ Mepivacaine containing $1: 100,000$ epinephrine using a special intraligamentary dental syringe with a 27 gauge short disposable needle $(0.2 \mathrm{ml}$ will be injected on each side of the tooth mesially and distally).

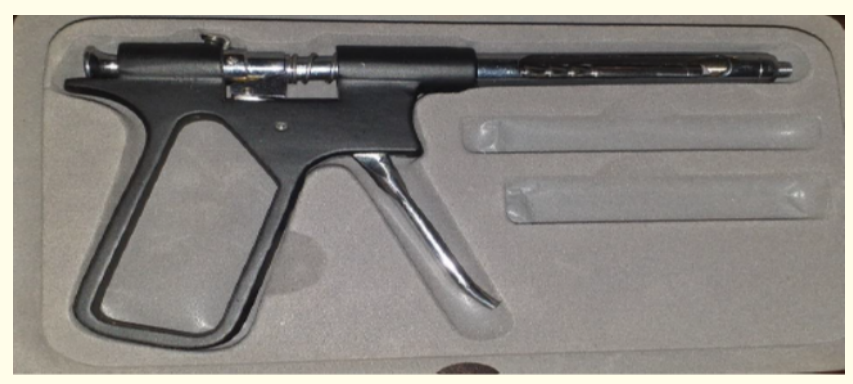

Figure 1: Intraligamentary syringe.

Using round bur size 3 and Endo-z bur an access cavity was done. Teeth will be isolated with rubber dam and the canals were negotiated with hand K-files of $2 \%$ taper number 10 and 15 . Working length will be detected using an electronic apex locator then intraoral periapical radiograph will be taken for confirmation of the working length, to be shorter than radiographic apex by $0.5-1 \mathrm{~mm}$.
Cleaning and shaping will be done using crown down preparation technique using protaper universal rotary files in the sequence of starting with S1 file without pressure in the coronal two thirds of the estimated working length, then use the SX file to resistance. Then use the S1 file to the full working length, renegotiate with K-file 15 to full working length. The rest of the files' sequence, S1, S2 in brushing action to laterally cut dentin in the coronal twothirds of the canal, then finishing files are used (F1, F2, F3) in the mesial canals in picking motion to the full working length while in the distal canals the preparation will be done till F4 or F5 finishing files. Endodontic motor was used according to the manufacturer's instructions with a rotational speed of $300 \mathrm{rpm}$ at different torque values.

The irrigation of the canals will be performed using $3 \mathrm{ml}$ of $2.5 \%$ Sodium hypochlorite between every succeeding instrument. Finally, $5 \mathrm{ml}$ of (2.5\% Sodium Hypochlorite, 17\% EDTA solution and distilled water) were used as a final flush to the canals. The mesial canals usually finished at F3 and the distal canals (all teeth had single distal canal) usually finished at F4 or F5. A 19\% EDTA gel was used on each file as a lubricant. Paper points were used for canal dryness after mechanical preparation.

Obturation was carried out using the cold lateral condensation technique with protaper guttapercha cones and resin sealer. A cotton pellet was put in the pulp chamber after obturation and the access cavity was sealed with a temporary filling to keep away from coronal leakage.

The patient were given a Numeric Rating Scale (Figure 2) and asked to rate his pain level at 4, 8, 12, 24 and 48 hours after root canal treatment. All patients received postoperative instructions. In case of moderate or severe pain, patients were instructed to call the operator and allowed to take ibuprofen 400mg (Brufen tablets, Abbott Pharmaceuticals, Italy), and instructed to record the number of analgesic tablets taken. The patients are asked to come after 7 days to deliver the NRS and to record the postoperative level of pain on percussion.

Data management and statistical analysis were carried out using the Statistical Package for Social Sciences (SPSS) version 24. Numerical data were summed up using means and standard deviations or medians and ranges. Data were surveyed for normality by inspecting the data distribution and using Kolmogorov-Smirnov 


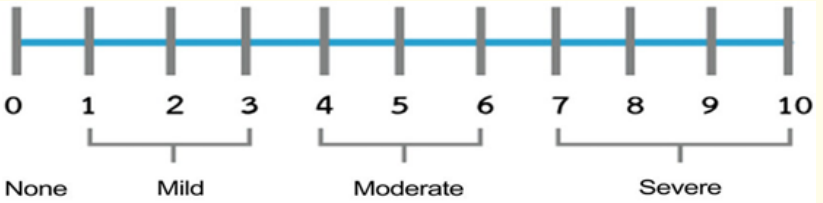

Figure 2: Numeric rating scale (NRS).

and Shapiro-Wilk tests. Categorical data were summarized as percentages. Differentiation between the 2 groups regarding normally distributed numeric variables were done using the t-test. MannWhitney test was used to contrast Non-normally distributed numeric variables. Comparisons over time regarding numeric variables were done by Friedman test and pairwise difference were detected by the Wilcoxon rank test. For categorical variables, differences were analyzed when suitable with Chi- square test and Fisher's exact test. Adjustments of $\mathrm{p}$ value were done using the Bonferroni method for multiple testing. All p-values are twosided. P-values $\leq 0.05$ were considered significant.

\section{Results}

Twenty-six patients with acute irreversible pulpitis and symptomatic apical periodontitis in mandibular molars participated in this study (10 males, 16 females).The patients were assigned into two equal groups in a random way (Group A experimental group: 13, Group B control group: 13).

The patients mean age in Group (A) was 32.0 5 5.8 years and range (25-44) while in Group (B) was 32.7 \pm 7.1 years and range (25-50). No significant difference was found between mean age values between the two groups ( $p=0.789)$. Gender distribution was identical in both Groups involved 8 males and 5 females. There was no significant difference between both groups table 1 .

\begin{tabular}{|c|c|c|c|c|c|c|}
\hline \multicolumn{2}{|c|}{ Group } & \multicolumn{2}{c|}{ Group A } & \multicolumn{2}{c|}{ Group B } & \multirow{2}{*}{$\begin{array}{c}\text { P } \\
\text { value }\end{array}$} \\
\hline \multicolumn{2}{|c|}{ Variables } & No & \% & No & $\%$ & \\
\hline \multirow{2}{*}{$\begin{array}{c}\text { Age } \\
\text { (yrs.) }\end{array}$} & Mean \pm SD & \multicolumn{2}{|c|}{$32.0 \pm 5.8$} & \multicolumn{2}{|c|}{$32.7 \pm 7.1$} & 0.789 \\
\cline { 2 - 6 } & Range & \multicolumn{2}{|c|}{$25-44$} & \multicolumn{2}{|c|}{$25-50$} & \\
\hline \multirow{2}{*}{ Sex } & Female & 8 & 61.5 & 8 & 61.5 & 1.000 \\
\cline { 2 - 6 } & Male & 5 & 38.5 & 5 & 38.5 & \\
\hline
\end{tabular}

Table 1: Age and gender distribution.
The experimental group has a statistically significant reduction in pain than control group except preoperatively and at 4 hours. Data of post-operative pain incidence at the different pain categories for the experimental and the control groups are presented in table 2 and figure 3. A significant decrease in postoperative pain intensity was detected in the experimental group compared with the control group after $8 \mathrm{~h}(\mathrm{P}=0.002)$, after $12 \mathrm{~h}(\mathrm{P}=<0.001)$, after $24 \mathrm{~h}(\mathrm{P}=0.016)$, after $48 \mathrm{~h}$.

\begin{tabular}{|c|c|c|c|c|c|c|}
\hline & & \multicolumn{2}{|c|}{ Group A } & \multicolumn{2}{|c|}{ Group B } & \multirow[b]{2}{*}{$P$ value } \\
\hline & & Count & $\%$ & Count & $\%$ & \\
\hline \multirow[t]{2}{*}{$\begin{array}{l}\text { Preopera- } \\
\text { tive }\end{array}$} & $\begin{array}{l}\text { Mild -Mod- } \\
\text { erate }\end{array}$ & 8 & 61.5 & 9 & 69.2 & 0.680 \\
\hline & Severe & 5 & 38.5 & 4 & 30.8 & \\
\hline \multirow[t]{2}{*}{ After $41 \mathrm{i}$} & Mild & 7 & 53.8 & 4 & 30.8 & 0.234 \\
\hline & $\begin{array}{c}\text { Moderate - } \\
\text { Severe }\end{array}$ & 6 & 46.2 & 9 & 69.2 & \\
\hline \multirow[t]{3}{*}{ After 81i } & None-Mild & 8 & 61.5 & 0 & 0.0 & 0.002 \\
\hline & Moderate & 4 & 30.8 & 6 & 46.2 & \\
\hline & Severe & 1 & 7.7 & 7 & 53.8 & \\
\hline \multirow[t]{3}{*}{ After $12 \mathrm{~h}$} & $\begin{array}{l}\text { None- } \\
\text { Mild }\end{array}$ & 10 & 76.9 & 0 & 0.0 & $<0.001$ \\
\hline & Moderate & 3 & 23.1 & 8 & 61.5 & \\
\hline & Severe & 0 & 0.0 & 5 & 38.5 & \\
\hline \multirow[t]{3}{*}{ After $24 \mathrm{~h}$} & None & 6 & 46.2 & 2 & 15.4 & 0.016 \\
\hline & Mild & 7 & 53.8 & 5 & 38.5 & \\
\hline & $\begin{array}{c}\text { Moderate- } \\
\text { Severe }\end{array}$ & 0 & 0.0 & 6 & 46.2 & \\
\hline \multirow[t]{3}{*}{ After $48 \mathrm{~h}$} & None & 10 & 76.9 & 3 & 23.1 & 0.012 \\
\hline & Mild & 3 & 23.1 & 6 & 46.2 & \\
\hline & $\begin{array}{c}\text { Moderate- } \\
\text { Severe }\end{array}$ & 0 & 0.0 & 4 & 30.8 & \\
\hline
\end{tabular}

Table 2: Comparison of pain for different pain categories between the two groups (experimental group A: piroxicam.) and (control group B: mepivacaine).

Pre-operatively, there was no statistically significant difference between the experimental group and the control group considering the pain on percussion $(\mathrm{p}=0.004)$. Post-operatively, experimental group A showed less pain on percussion intensity than control group $B$. The median and range of the NRS scores was $0(0-3)$ for the experimental group (A) and $3(0-5)$ for the control group 


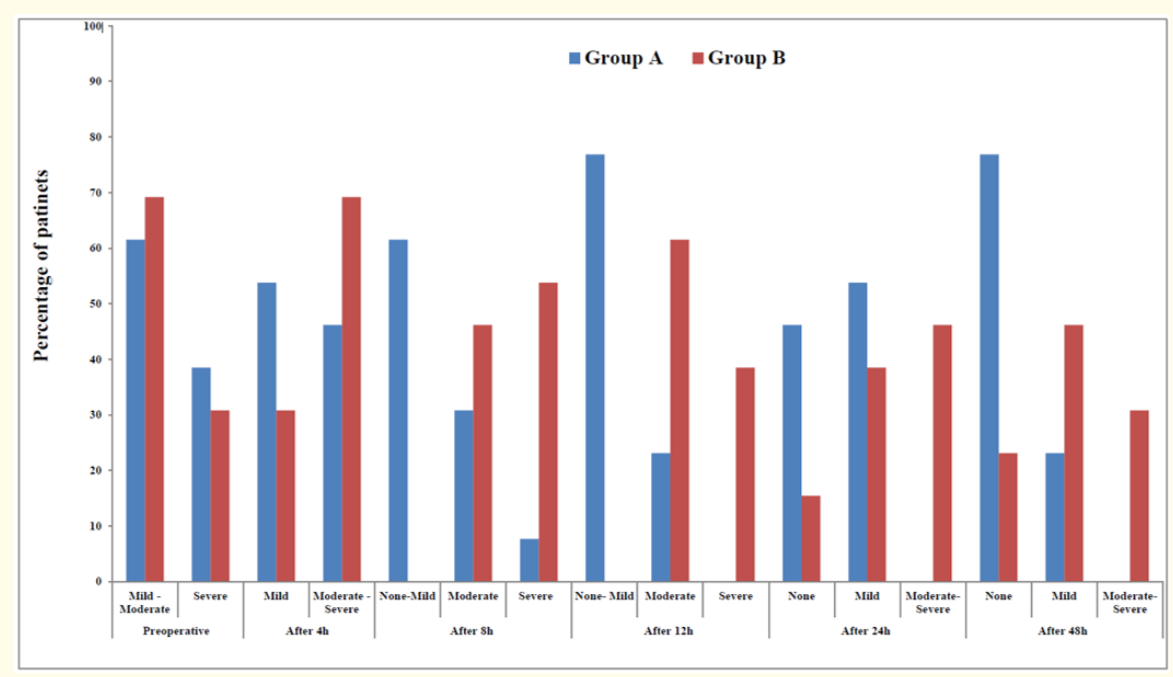

Figure 3: Bar chart comparison of pain for different pain categories between the two groups (Experimental Group A, Control Group B).

(B) with statistically significant difference between both groups ( $p$ $=0.004$ ) (Table 3).

\begin{tabular}{|l|c|c|c|c|c|c|c|}
\hline \multirow{2}{*}{$\begin{array}{c}\text { Groups dif- } \\
\text { ferent times }\end{array}$} & \multicolumn{3}{|c|}{ Group A (n = 13) } & \multicolumn{3}{c|}{ Group B (n = 13) } & \\
\cline { 2 - 8 } & Median & Min. & Max. & Median & Min. & Max & $\begin{array}{c}\text { P } \\
\text { value 1 }\end{array}$ \\
\hline $\begin{array}{l}\text { Preoperative } \\
\text { pain }\end{array}$ & 5 & 2 & 9 & 5 & 1 & 8 & 0.362 \\
\hline $\begin{array}{l}\text { Post-opera- } \\
\text { tive }\end{array}$ & 0 & 0 & 3 & 3 & 0 & 5 & 0.004 \\
\hline P value 2 & \multicolumn{3}{|c|}{0.002} & \multicolumn{3}{|c|}{0.011} & \\
\hline
\end{tabular}

Table 3: Median and range of NRS score of percussion pre and postoperative in the tested groups.

Regarding the drug intake, for experimental group A; 6 patients (46.2\%) and for control group B 12 patients (92.1\%) received analgesics. There was statistical significant lower analgesic intake in group $A(p=0.030)$.

\begin{tabular}{|c|c|c|c|c|c|c|}
\hline \multicolumn{2}{|c|}{ Group } & \multicolumn{2}{c|}{ Group A } & \multicolumn{2}{c|}{ Group B } & \\
\hline \multicolumn{2}{|c|}{ Variables } & No & \% & No & \% & P value \\
\hline Analgesic & No & 7 & 53.8 & 1 & 7.7 & 0.030 \\
\cline { 2 - 7 } & Yes & 6 & 46.2 & 12 & 92.1 & \\
\hline Analgesic no. & Median (range) & \multicolumn{2}{|c|}{$1(1-2)$} & $4(2-7)$ & 0.001 \\
\hline
\end{tabular}

Table 4: Comparison drug intake for the tested groups (Experimental group A, control group B).

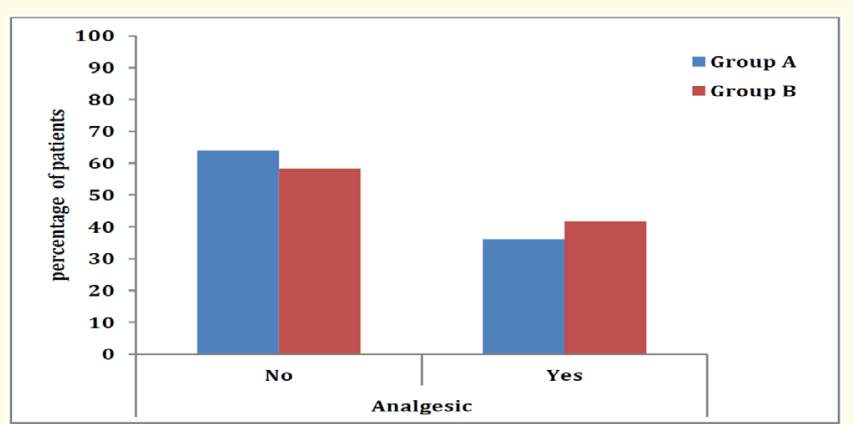

Figure 4: Bar chart representing analgesic intake distribution in the tested groups (Experimental group A, Control group B).

\section{Discussion}

Postoperative pain is a major concern for both the patient and the dentist in spite of recent advances in the field of endodontics [13]. So, it is important to understand the pain pathways related to pulpoperiapical disease in order to achieve proper pain control during and after treatment as persistent pain after endodontic therapy may lead to patient dissatisfaction [14]. Postoperative pain has been appeared to be occurred in a range from 25 to $40 \%$. This post-endodontic pain usually result from instrumentation and/or obturation [1]. During instrumentation, extrusion of microorganisms or debris is common and will lead to elevation of the inflammatory response. These course of actions lead to the production of inflammatory mediators including prostaglandins [15].

$\mathrm{P}<0.05$ is significant. 
Pain control using a lot of ways as pharmacological and physiological methods present to decrease pain and discomfort after endodontic treatment. Many categories of drugs have been explored for management of post treatment pain [16]. These involve nonnarcotic analgesics including NSAIDs and acetaminophens, opioids and steroids. Multiple systematic reviews have proved that NSAIDs show effective analgesic reaction in patients who withstand this category of drugs. There is powerful evidence for the use of NSAIDs as a main class of analgesics for acute inflammatory pain management in case of either surgical or non-surgical endodontic procedures [17]. The prevention of the inflammatory process is one of the most effective methods to decrease or inhibit pain during and after endodontic treatment [18].

Piroxicam, a member of the oxicam group of NSAIDs with antiinflammatory, analgesic and anti-pyretic properties may be effective in post-endodontic pain management. The post-endodontic pain is frequently severe in the first 24 hours after treatment, then it will decrease in gradual way until usually disappearing after 7-10 days in almost all the cases. And since piroxicam has a half-life of $50 \mathrm{~h}$ in the plasma, it will be has a major role in managing the most severe pain which presents after endodontic treatment [19]. It is also showed that the intraligamentary injection allows the administration of anti-inflammatory agents immediately in the periapical intraosseous area [20]. Symptomatic apical periodontitis is more prone to post-operative pain as teeth with pre-operative pain are more associated with post-operative pain [21,22]. Achievement of adequate bacterial eradication in single visit endodontic treatment remains a controversy. Gill., et al. (2016) [23] proved that there is no difference in periapical healing between single-visit treatment and multi-visit treatment in teeth with symptomatic apical periodontitis.

The results of our study demonstrated that prophylactic intraligamentary injection of piroxicam was much more better in decreasing pain after endodontic treatment and there was statistically significant difference in NRS scores of pain score at $8(\mathrm{p}<0.001)$, $12(p<0.001), 24(p=0.002)$ and $48(p=0.002)$ hours.

Our results are in agreement with the findings of a study of Atbaei and Mortazavi [3] which shows a statistically significant reduction of post-operative pain intensity in the group that received intraligamentary piroxicam compared with the control group at all times recorded - after 4 hours $(P=0.025)$, after 8 hours $(P=0.001)$, after 12 hours $(\mathrm{P}=0.002)$, after 24 hours $(\mathrm{P}=0.011)$ and after 48 hours $(\mathrm{P}=0.031)$. The anaesthesia used in Altaebi study was $0.4 \mathrm{~mL}$ of $2 \%$ lidocaine carpule containing 1:80,000 epinephrine whereas in our present study, mepivacaine carpules having a concentration of 1:200,000 levonordefrin was used. The amount of piroxicam in both studies was the same.

The results in this study was also in agreement with the findings of the study of Subhan and Shami (2016) [24] in which the piroxicam group showed significant decrease in pain intensity after 48 hours (Mean $\pm \mathrm{SD}=0.40 \pm 0.49$ ) in comparison with the control group having mean pain values of $1.37( \pm 0.93)$ at 48 hours.

Although limited in literature, the use of intraligamentary method for administration of agents other than local anesthetics has been proved to be effective and the encouragement for studying the role of intraligamentary injection method to control the pain after endodontic treatment came from studies which showed that direct administration of anti-inflammatory drugs into the periapical intraosseous area is a very beneficial method of pain management [16,20,24-26]. The results of the present study was in agreement with a study conducted by Joshi., et al. (2016) compared the effectiveness of oral and intraligamentary piroxicam in decreasing pain after endodontic treatment [16]. The difference in reduction of pain by either oral or intraligamentary piroxicam was not very significant in the initial 8 hours but at time points 12, 24 and 48 hours intraligamentary piroxicam was much more higher in decreasing post treatment pain. Results of the present study are in agreement with that of other studies where intraligamenatary NSAID's have showed to have a significant effect in controlling postoperative pain. This is due to $100 \%$ pharmacokinetics of the active agent at the target site, supporting the role of piroxicam in managing postendodontic pain.

The study of Kaufman., et al. [24] proved that intraligamentary administration of low doses of long-acting methylprednisolone significantly decrease postoperative pain in different clinical situations, either irreversible pulpitis or acute apical periodontitis within a 24-hour follow up. The intraligamentary administration was found to be advantageous, particularly in cases when the patient is treated in one visit or when fast pain prevention is required.

Raksha., et al. (2013) [27] proved that Prophylactic intraligamentary injection of $0.4 \mathrm{ml}$ of $30 \mathrm{mg}$ of Diclofenac Sodium was found to have a remarkable effect in decreasing post-endodontic pain of 
vital teeth with irreversible pulpitis during the first 48 hours after single visit root canal treatment. It was far more effective than the same Lidocaine injection in decreasing postoperative endodontic pain which support the prophylactic use of intraligamentary antiinflammatory agents in managing postendodontic pain. Regarding postoperative pain on percussion, intraligamentary piroxicam has a lower level of pain compared to the control group and there was statistically significant difference.

Results were in agreement with the results of Paredes., et al. (2018) [26] that showed that a single dose of preoperative ketorolac was as effective nonsteroidal anti-inflammatory drug for the relief of pain after single visit root canal treatment in teeth with symptomatic apical periodontitis. In the current study, participants in the piroxicam group used less number of analgesic tablets than control group. There was statistical significant difference between the two groups ( $\mathrm{p}=0.030)$. This study was limited by the small sample size and within the conditions of this study, it could be concluded that the pre-operative prophylactic intraligamentary piroxicam can reduce post-operative pain, pain on percussion and the total number of analgesic tablets taken for patients with mandibular posterior teeth with acute irreversible pulpitis and symptomatic apical periodontitis. The measurement of pain is complicated because pain discrimination is subjective and different which is controlled by many physical and psychological factors [14]. Further clinical studies investigating the efficacy of other NSAID groups should be conducted to explore the most successful drug for relieving pain after endodontic treatment.

\section{Conclusion}

Within the limitations of this study, it could be concluded that the prophylactic administration of intraligamentary piroxicam has a significant effect on decreasing post-endodontic pain for vital teeth with irreversible pulpitis and symptomatic apical periodontitis in mandibular molar teeth during the first 48 hours. Also, has reduced pain on percussion and number of analgesic tablets taken. It had more significant results in pain relief than a similar mepivacaine injection hence should be considered as an successful method of managing post endodontic pain.

\section{Bibliography}

1. Nazaroglou I., et al. "Postoperative pain in dentistry: a review". Surgery Journal 3 (2008): 96-103.
2. Ehrmann EH., et al. "Flare-ups in endodontics and their relationship to various medicaments". Australian Endodontic Journal 33 (2007): 119-130.

3. Kohli D., et al. "Postendodontic pain: a practical approach to diagnosis and management". Quintessence International 52.5 (2021): 384-392.

4. Shirvani A., et al. "The efficacy of non-narcotic analgesics on post-operative endodontic pain: A systematic review and meta-analysis". Journal of Oral Rehabilitation 44 (2017): 709-721.

5. Smridhi Bhanot., et al. "Antibiotics and Analgesics in Endodontics-A Review". IAR Journal of Medical Sciences 2.1 (2021): 1323.

6. Sadaf D and Ahmad MZ. "Factors Associated with Postoperative Pain in Endodontic Therapy". IJBS 10.4 (2014): 243-247.

7. Mohammadi Z., et al. "Pharmacological strategies to control post-operative endodontic pain". Dental Research Journal 4 (2007): 61-68.

8. Elzaki WM., et al. "Double-blind Randomized Placebo-controlled Clinical Trial of Efficiency of Nonsteroidal Anti-inflammatory Drugs in the Control of Post-endodontic Pain". Journal of Endodontics 42.6 (2016): 835-842.

9. Ong KS and Seymour RA. "Maximizing the safety of Nonsteroidal Antii inflammatory Drug Use for Postoperative Dental Pain: An Evidence-based Approach". Anesthesia Progress 5 (2003): 62-74.

10. Mohammadi Z., et al. "Pharmacological Control post-operative Endodontic Pain”. Dental Research Journal 4.2 (2007): 61-68.

11. O'Brien TP., et al. "Effect of A Non-Steroidal Anti-Inflammatory Drug on Tissue Levels of Immunoreactive Prostaglandin E2, Immunoreactive Leukotriene, and pain after Periodontal Surgery". Journal of Periodontology 67 (1996): 1307-1316.

12. Brunton LL., et al. "Goodman and Gilman's The Pharmacological Basis of Therapeutics". 11th ed. NewYork: McGraw Hill, Medical Publishing Devision (2006).

13. Schulz KF., et al. "CONSORT 2010 Statement: updated guidelines for reporting parallel group randomised trials". $B M C$ Medicine 8 (2010): 18. 
14. Mokhtari F., et al. "Effect of Premedication with Indomethacin and Ibuprofen on Postoperative Endodontic Pain: A Clinical Trial". Iranian Endodontic Journal 11.1 (2016): 57-62.

15. Ramesh S. "Pain management in endodontics". Journal of Pain and Symptom Management 6.4 (2013): 281-289.

16. Joshi N., et al. "Comparative evaluation of the efficacy of two modes of delivery of Piroxicam for the management of postendodontic pain: A randomized control trial". Journal of Conservative Dentistry 19.4 (2016): 301-305.

17. Hargreaves KM., et al. "Pharmacologic Management of Endodontic Pain". In: Ingle JI, Backland LK, Baumgartner JC. Endodontics. 6th ed. Hamilton: Ontario, (2008): 713-736.

18. Khan AA and Dionne RA. "Cox-2 inhibitors for endodontic pain". Endodontic Topics 3 (2002): 31-40.

19. Armando Maccango MD., et al. "Double-blind controlled clinical trial of oral s-adenosylmethionine versus piroxicam in knee osteoarthritis". American Journal of Medicine 83.5 (1987): 7277.

20. Adnan Atbaei and Nazanin Mortazavi. "Prophylactic intraligamentary injection of piroxicam (feldene) for management of post endodontic pain in molar teeth with irreversible pulpitis". Australian Endodontic Journal 38.1 (2012): 31-35.

21. Law AS., et al. "Predicting severe pain after root canal therapy in the National Dental PBRN". Journal of Dental Research 94 (2015): 37S-43S.

22. Sipavičiūtė E and Manelienè R. "Pain and flare-up after endodontic treatment procedures". Stomatologija Baltic Dental and Maxillofacial Journal 16.1 (2014): 25-30.

23. Gill GS., et al. "Single Versus Multi-visit Endodontic Treatment of Teeth with Apical Periodontitis". Annals of Medical and Health Science Research 6.1 (2016): 19-26.

24. Kaufman E., et al. "Intraligamentary anaesthesia: a clinical study". Journal of Prosthetic Dentistry 49 (1983): 337-339.

25. SUBHAN ZAINAB., et al. "Comparison of Prophylactic Intraligamentary Injection of Piroxicam and Lignocaine for Management of Postoperative Endodontic Pain". Pakistan Oral and Dental Journal 36.3 (2016): 480-483.
26. Jorge Paredes Vieyra., et al. "The Outcome of Preoperative Administration of Single-dose Ketorolac, Non-steroidal Antiinflammatory Drug and Placebo on Postoperative Pain in Teeth with Irreversible Pulpitis and Apical Periodontitis". Oral Health and Dentistry 2.4 (2018): 410-420.

27. Raksh Bhat., et al. "Evaluation of the efficiency of Intraligamentary Diclofenac Sodium in reducing postoperative endodontic pain in patients with irreversible pulpitis". International Research Journal of Pharmacy 4 (2013): 237-239.

Volume 5 Issue 12 December 2021

(C) All rights are reserved by Hend Hassan Swellam., et al. 